\title{
Accuracy of thymine-thymine dimer bypass by Saccharomyces cerevisiae DNA polymerase $\boldsymbol{\eta}$
}

\author{
M. Todd Washington, Robert E. Johnson, Satya Prakash, and Louise Prakash*

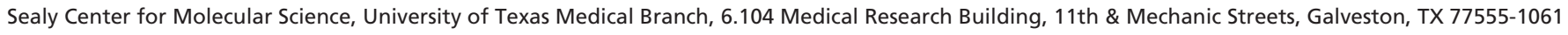

Edited by Charles M. Radding, Yale University School of Medicine, New Haven, CT, and approved January 5, 2000 (received for review November 11, 1999)

The Saccharomyces cerevisiae RAD30 gene functions in error-free replication of UV-damaged DNA. RAD30 encodes a DNA polymerase, Pol $\eta$, which inserts two adenines opposite the two thymines of a cis-syn thymine-thymine (T-T) dimer. Here we use steady-state kinetics to determine the accuracy of DNA synthesis opposite the T-T dimer. Surprisingly, the accuracy of DNA synthesis opposite the damaged DNA is nearly indistinguishable from that opposite nondamaged DNA, with frequencies of misincorporation of about $10^{-2}$ to $10^{-3}$. These studies support the hypothesis that unlike most DNA polymerases, Pol $\eta$ is able to tolerate distortions in DNA resulting from damage, which then enables the polymerase to utilize the intrinsic base pairing ability of the T-T dimer.

U $\mathrm{V}$ radiation generates DNA lesions, which if uncorrected, lead to mutations and cancer formation. In both prokaryotes and eukaryotes, UV-induced DNA lesions are removed by nucleotide-excision repair, a mechanism that incises the damaged DNA strand on both sides of the lesion and results in the release of the damage in an oligodeoxynucleotide fragment (1). Mutations in the human nucleotide-excision repair genes result in the cancer-prone genetic disorder xeroderma pigmentosum (XP).

Because unrepaired UV-induced DNA lesions in the template strand block replicative DNA polymerases, organisms have evolved ways to bypass these lesions, one of which is mutagenic translesion synthesis (TLS). In Escherichia coli, mutagenic TLS requires the $\mathrm{UmuD}_{2}{ }_{2} \mathrm{C}$ complex $(2,3)$, and in eukaryotes, mutagenic TLS is performed by the error-prone Rev3- and Rev7-encoded DNA polymerase, Pol $\zeta$ (4). Recently, it has emerged that in eukaryotes, TLS can also be error-free. In Saccharomyces cerevisiae, error-free damage bypass is accomplished by the RAD30-encoded DNA polymerase $\eta$ that efficiently replicates DNA across from a cis-syn thymine-thymine (T-T) dimer, a predominant form of UV-induced DNA lesion, by preferentially inserting two adenines opposite the T-T dimer (5). Deletion of yeast $R A D 30$ results in a moderate increase in UV sensitivity and an increase in the frequency of UV-induced mutations $(6,7)$. In humans, mutational inactivation of $h R A D 30 A$ causes the variant form of XP (XP-V) $(8,9)$. XP-V cells are hypermutable with UV light; they are deficient in bypass replication of DNA containing a cis-syn T-T dimer (10-13). As a consequence, $\mathrm{XP}-\mathrm{V}$ individuals suffer from a high incidence of sunlight-induced skin cancers.

Although Pol $\eta$ preferentially inserts two adenines opposite the T-T dimer, it is unclear how accurate the translesion DNA synthesis of Pol $\eta$ is. Because studies of the accuracy of Pol $\eta$ bypass relied on DNA sequence analysis of the bypass products (5), they did not provide a quantitative measure of error frequencies. Here, we use steady-state kinetics to measure the fidelity of Pol $\eta$ for deoxynucleotide incorporation opposite the undamaged and damaged TT residues. Our results show that Pol $\eta$ misincorporates opposite the cis-syn T-T dimer with nearly the same frequency as it does opposite the nondamaged template bases, $\approx 10^{-2}$ to $10^{-3}$. From these data, we conclude that Pol $\eta$ synthesizes DNA in a manner that is indifferent to the DNA distortion caused by the T-T dimer, and this property enables the polymerase to utilize the intrinsic base-pairing ability of the dimer.

\section{Materials and Methods}

Synthetic Oligodeoxynucleotides. The following two oligomers, 44 and $45 \mathrm{nt}$ long, were used as primers. 44 mer, 5'-GTTTT CCCAG TCACG ACGAT GCTCC GGTAC TCCAG TGTAG GCAT; 45 mer, 5' -GTTTT CCCAG TCACG ACGAT GCTCC GGTAC TCCAG TGTAG GCATA. For the template strand, we used the following 75-nt oligomer: 5'-AGCTA CCTAG CCTGC ACGAA GAGTT CGTAT TATGC CTACA CTGGA GTACC GGAGC ATCGT CGTGA CTGGG AAAAC, in which the underlined $T$ residues were either undamaged or they formed a cis-syn T-T dimer. The primer oligomers were $5^{\prime}$ ${ }^{32} \mathrm{P}$-end-labeled by using polynucleotide kinase (Boehringer Mannheim) and $\left[\gamma_{-}{ }^{32} \mathrm{P}\right] \mathrm{ATP}$, and annealed by mixing a $0.10 \mu \mathrm{M}$ concentration of the labeled primer with a $0.15 \mu \mathrm{M}$ concentration of the nonlabeled template in $50 \mathrm{mM}$ Tris $\cdot \mathrm{HCl}(\mathrm{pH} 7.5)$ containing $100 \mathrm{mM} \mathrm{NaCl}$ at $90^{\circ} \mathrm{C}$ for 2 min followed by cooling to $25^{\circ} \mathrm{C}$ over several hours. The resulting four DNA substrates are shown in Fig. 1.

Purification of Pol $\boldsymbol{\eta}$. Pol $\eta$ was expressed and purified from the yeast strain BJ5464 as described $(5,7)$.

Deoxynucleotide Incorporation Assays. The 5' ${ }^{32} \mathrm{P}$-end-labeled primer-template substrate $(10 \mathrm{nM})$ and various concentrations of each deoxynucleotide $(0-500 \mu \mathrm{M})$ were incubated in $25 \mathrm{mM}$ $\mathrm{NaPO}_{4}(\mathrm{pH} 7.0) / 5 \mathrm{mM} \mathrm{MgCl} / 5 \mathrm{mM}$ DTT $/ 100 \mu \mathrm{g} / \mathrm{ml} \mathrm{BSA} /$ $10 \%$ glycerol at $25^{\circ} \mathrm{C}$. Reactions were initiated by adding Pol $\eta$ $(1 \mathrm{nM})$. Reactions were terminated after $5 \mathrm{~min}$ by adding 10 volumes of formamide-loading buffer (80\% deionized formamide $/ 10 \mathrm{mM}$ EDTA, $\mathrm{pH} 8.0 / 1 \mathrm{mg} / \mathrm{ml}$ xylene cyanol $/ 1 \mathrm{mg} / \mathrm{ml}$ bromophenol blue). Quenched samples were heated at $90^{\circ} \mathrm{C}$ for 2 min, placed on ice, and loaded onto a $10 \%$ polyacrylamidesequencing gel containing $6 \mathrm{M}$ urea.

Analysis of Fidelity. Fidelity was calculated from the deoxynucleotide incorporation kinetics as described (14). Gel-band intensities of the substrate and products were quantitated by using a PhosphorImager and IMAGEQUANT software (Molecular Dynamics). The observed rate of deoxynucleotide incorporation, $V_{\text {obs, }}$ was determined by dividing the relative amount of product formed by the 5-min incubation period. The deoxynucleotideincorporation reactions were linear with time under these conditions. The $V_{\text {obs }}$ was plotted as a function of the deoxynucleotide

\footnotetext{
This paper was submitted directly (Track II) to the PNAS office.

Abbreviations: $\mathrm{XP}$, xeroderma pigmentosum; $\mathrm{XP}-\mathrm{V}$, variant form of $\mathrm{XP}$; TLS, translesion synthesis; T-T dimer, thymine-thymine dimer.

*To whom reprint requests should be addressed. E-mail: Iprakash@scms.utmb.edu.

The publication costs of this article were defrayed in part by page charge payment. This article must therefore be hereby marked "advertisement" in accordance with 18 U.S.C. $\S 1734$ solely to indicate this fact.

Article published online before print: Proc. Natl. Acad. Sci. USA, 10.1073/pnas.050491997. Article and publication date are at www.pnas.org/cgi/doi/10.1073/pnas.050491997
} 


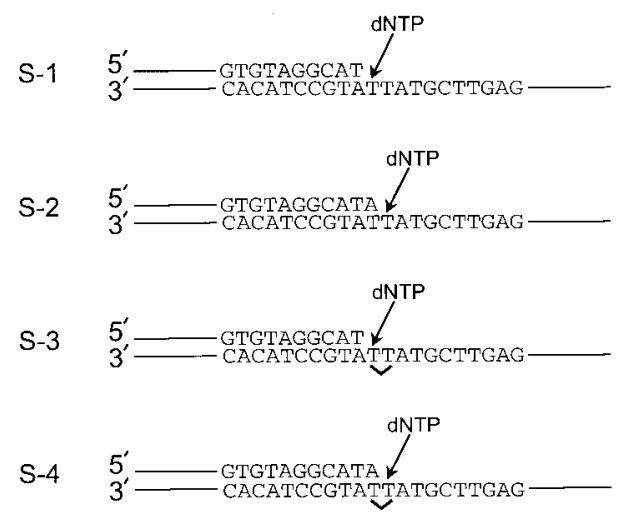

Fig. 1. DNA substrates used to assay Pol $\eta$ fidelity. The nondamaged and damaged DNA substrates are shown. The position of the cis-syn T-T dimer in substrates S-3 and S- 4 is indicated by $a v$. The first T and second T of the cis-syn T-T dimer or the identical nondamaged sequence refer to the first and second $T$ residues encountered by the DNA polymerase by using that strand as a template.

concentration and data were fit to the Michaelis-Menten equation describing a hyperbola:

$$
V_{\mathrm{obs}}=\left(V_{\max } \times[\mathrm{dNTP}]\right) /\left(K_{\mathrm{m}}+[\mathrm{dNTP}]\right) .
$$

From the best-fit curve, the apparent $K_{\mathrm{m}}$ and $V_{\max }$ steady-state kinetic parameters for both the incorrect and correct deoxynucleotides were obtained, and these parameters were used to calculate the frequency of deoxynucleotide misincorporation, $f_{\text {inc }}$, by using the following equation (14):

$$
f_{\text {inc }}=\left(V_{\max } / K_{\mathrm{m}}\right)_{\text {incorrect }} /\left(V_{\max } / K_{\mathrm{m}}\right)_{\text {correct }} .
$$

Processivity Assay. Processivity was measured by preincubating Pol $\eta(20 \mathrm{nM})$ with the 5' ${ }^{32} \mathrm{P}$-end-labeled DNA substrate in deoxynucleotide-incorporation reaction buffer for $15 \mathrm{~min}$ at $25^{\circ} \mathrm{C}$. The reaction was initiated by adding all four deoxynucleotides (200 $\mu \mathrm{M}$ each), $5 \mathrm{mM} \mathrm{MgCl}_{2}$, and excess nonradiolabeled herring sperm DNA $(1 \mathrm{mg} / \mathrm{ml})$ as a trap. To demonstrate the effectiveness of the trap, we performed a control reaction in which Pol $\eta$ was preincubated with the herring sperm DNA trap and the 5' ${ }^{32} \mathrm{P}$-end-labeled DNA substrate before initiation of the reaction with the deoxynucleotides and $\mathrm{MgCl}_{2}$. After various reaction times, the reactions were quenched and subjected to gel electrophoresis as described for the deoxynucleotide-incorporation assays.

Analysis of Processivity. Processivity was calculated by a modification of the procedure described (15). Briefly, gel-band intensities of each of the extended primers at the 120-s time point of the processivity assay were quantitated and used to calculate the percent of active polymerases that incorporated at least $N$ deoxynucleotides by using the following equation:

$$
\text { \% active polymerases at } \begin{aligned}
n= & \left(I_{\mathrm{N}}+I_{\mathrm{N}+1}+\ldots\right) \times 100 \% /\left(I_{1}\right. \\
& \left.+I_{2}+\ldots+I_{\mathrm{N}}+\ldots\right),
\end{aligned}
$$

where $I_{1}$ is the intensity of the band resulting from one incorporation, $I_{N}$ is the intensity of the band resulting from $N$ incorporations, and so on. Processivity, $P_{N}$, is defined as the probability at deoxynucelotide incorporation $N$ of the polymerase moving ahead to incorporate the $N+1$ deoxynucleotide rather than dissociating from the DNA template (15). This can be expressed by the ratio of active polymerases at $N$ that are also active at $N+1$, which is given by the following equation:

$$
\begin{aligned}
P_{N}= & \% \text { active polymerase at } N \\
& +1 / \% \text { active polymerase at } N .
\end{aligned}
$$

Substituting Eq. 3 into Eq. 4 results in an expression for $P_{N}$ in terms of gel-band intensities, and this equation was used to calculate the processivity:

$$
P_{\mathrm{N}}=\left(I_{N+1}+I_{N+2}+\ldots\right) /\left(I_{N}+I_{N+1}+I_{N+2}+\ldots\right) .
$$

\section{Results}

Fidelity Opposite Nondamaged Templates. Fidelity is a measure of the preference of a DNA polymerase for inserting the deoxynucleotide that forms a correct base pair with the template rather than the deoxynucleotides that form incorrect base pairs with the template $(14,16,17)$. Here we use the steady-state kinetics assay (14) to measure the fidelity of Pol $\eta$ for deoxynucleotide incorporation opposite the first and second $\mathrm{T}$ in a nondamaged DNA template (substrates S-1 and S-2; Fig. 1) and in a template of identical sequence containing a cis-syn T-T dimer (substrates S-3 and S-4; Fig. 1).

The rate of each deoxynucleotide incorporation opposite a template $\mathrm{T}$ was measured over a broad range of deoxynucleotide concentrations. For the incorrect deoxynucleotides (dGTP, dTTP, and dCTP), the concentrations were varied from 10 to
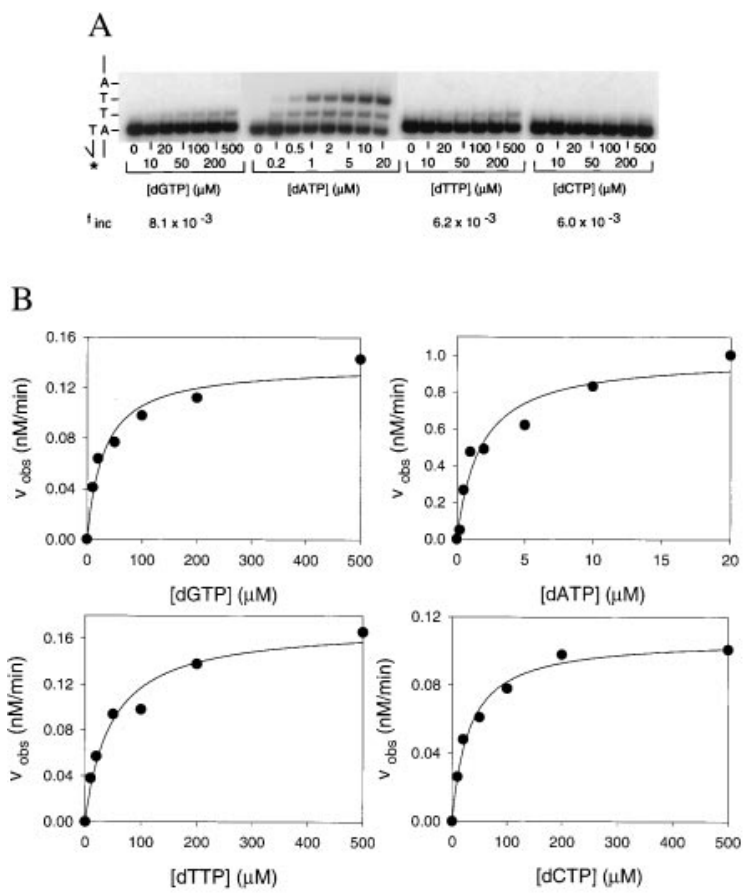

Fig. 2. Fidelity of Pol $\eta$ opposite the first nondamaged template T. $(A)$ Deoxynucleotide incorporation across from the first of two adjacent, nondamaged template T bases (substrate S-1; Fig. 1). Pol $\eta(1 \mathrm{nM})$ was incubated for $5 \mathrm{~min}$ at $25^{\circ} \mathrm{C}$ with the primer-template DNA $(10 \mathrm{nM})$ and with increasing concentrations of the incorrect deoxynucleotide (dGTP, dTTP, and dCTP; 0 to $500 \mu \mathrm{M}$ ) or the correct deoxynucleotide (dATP; 0 to $20 \mu \mathrm{M}$ ). The reactions were stopped and examined by denaturing PAGE. A portion of the template sequence is shown on the left. The asterisk indicates the ${ }^{32} \mathrm{P}$-labeled $5^{\prime}$ end of the primer. $(B)$ Quantitation of deoxynucleotide incorporation reactions. The observed rate of deoxynucleotide incorporation is plotted as a function of concentration for each of the deoxynucleotides. The data were fit by using Eq. 1 , and the $V_{\max }$ and $K_{\mathrm{m}}$ parameters obtained from the fit are listed in Table 1. 
$500 \mu \mathrm{M}$, whereas for the correct deoxynucleotide (dATP), the concentrations were varied from 0.2 to $20 \mu \mathrm{M}$. Apparent $K_{\mathrm{m}}$ and $V_{\max }$ steady-state parameters were obtained for the correct and incorrect deoxynucleotides as described in Materials and Meth$o d s$, and from these parameters the frequency of incorrect deoxynucleotide incorporation, $f_{\text {inc }}$, was calculated by using Eq. $2(14,18)$.

Fig. $2 A$ shows the pattern of deoxynucleotide incorporation opposite the first nondamaged template $\mathrm{T}$ (substrate S-1; Fig. 1). At low concentrations of dATP, many of the primers were extended by one or two deoxynucleotides, whereas at high deoxynucleotide concentrations of dGTP, dTTP, and dCTP, some of the primers were extended by one deoxynucleotide (Fig. $2 A)$. In Fig. $2 B, V_{\text {obs }}$ is plotted as a function of dNTP concentration, and from these data, the $V_{\max }$ and $K_{\mathrm{m}}$ parameters were obtained. For dATP incorporation opposite the first nondamaged template T, the apparent $K_{\mathrm{m}}$ was $1.7 \mu \mathrm{M}$ and the $V_{\max }$ was $1.0 \mathrm{nM} / \mathrm{min}$ (Table 1). For dGTP incorporation opposite the first nondamaged template T, the apparent $K_{\mathrm{m}}$ was $30 \mu \mathrm{M}$ and the $V_{\max }$ was $0.14 \mathrm{nM} / \mathrm{min}$. Thus, the frequency, $f_{\text {inc }}$, of misincorporating a $\mathrm{G}$ opposite the first nondamaged template $\mathrm{T}$ residue is $8.1 \times 10^{-3}$ (Table 1 ). Likewise, the frequency of misincorporating a $\mathrm{T}$ opposite the first nondamaged template $\mathrm{T}$ residue is $6.2 \times 10^{-3}$, and the frequency of misincorporating a Copposite the first nondamaged template T residue is $6.0 \times 10^{-3}$ (Table 1).

The pattern of deoxynucleotide incorporation opposite the second nondamaged template $\mathrm{T}$ (substrate S-2; Fig. 1) was similarly examined, and the $V_{\max }$ and apparent $K_{\mathrm{m}}$ parameters are listed in Table 1 . In this case, the frequency, $f_{\text {inc, of }}$ misincorporating a $\mathrm{G}, \mathrm{T}$, or $\mathrm{C}$ opposite the second nondamaged template $\mathrm{T}$ residue is $1.4 \times 10^{-3}, 3.7 \times 10^{-3}$, and $6.6 \times 10^{-3}$, respectively. The $f_{\text {inc }}$ values for the second nondamaged template $\mathrm{T}$ differ little from those for the first nondamaged template $\mathrm{T}$.

Fidelity Opposite Damaged Templates. Next, we measured the fidelity of Pol $\eta$ on substrates of identical sequence except that they contained a cis-syn T-T dimer (Fig. 1). Fig. $3 A$ shows the pattern of deoxynucleotide incorporation opposite the first template $\mathrm{T}$ of the $\mathrm{T}-\mathrm{T}$ dimer (substrate S-3; Fig. 1). As on nondamaged DNA, at low concentrations of dATP, many of the primers were extended by one or two deoxynucleotides, whereas at high concentrations of dGTP, dTTP, and dCTP, some of the primers were extended by one deoxynucleotide (Fig. $3 A$ ). From the $V_{\max }$ and apparent $K_{\mathrm{m}}$ parameters obtained from the fit shown in Fig. $3 B$ and listed in Table 1 , the frequency, $f_{\text {inc, of }}$ misincorporating a $\mathrm{G}, \mathrm{T}$, or $\mathrm{C}$ opposite the first template $\mathrm{T}$ residue of the T-T dimer was determined to be $5.2 \times 10^{-3}, 1.0 \times$ $10^{-3}$, and $8.3 \times 10^{-3}$, respectively (Table 1 ). These $f_{\text {inc }}$ values are quite similar to the $f_{\text {inc }}$ values for the first template $\mathrm{T}$ in the nondamaged DNA (Table 1 ).

The pattern of deoxynucleotide incorporation opposite the second template $\mathrm{T}$ of the $\mathrm{T}-\mathrm{T}$ dimer (substrate S-4; Fig. 1) was also quite similar to that in the undamaged DNA. From the $V_{\max }$ and apparent $K_{\mathrm{m}}$ parameters, the respective $f_{\text {inc }}$ values for misincorporating a $\mathrm{G}, \mathrm{T}$, or $\mathrm{C}$ are $4.6 \times 10^{-3}, 6.2 \times 10^{-4}$, and $4.3 \times 10^{-3}$ (Table 1$)$.

The ability of Pol $\eta$ to replicate the damaged and nondamaged DNA with nearly the same accuracy and efficiency is further illustrated in Fig. 4, which compares the $V_{\max } / K_{\mathrm{m}}$ parameter for the incorporation of $\mathrm{G}, \mathrm{A}, \mathrm{T}$, and $\mathrm{C}$ opposite each of the damaged and nondamaged template $\mathrm{T}$ residues. The residue $\mathrm{A}$ is incorporated to nearly the same extent opposite all four template $\mathrm{T}$ residues, and $\mathrm{C}$ is incorporated to nearly the same extent opposite all four template T residues. Opposite the second nondamaged template $\mathrm{T}$ residue, $\mathrm{G}$ is incorporated to a lesser extent (three- to fivefold) than it is opposite the other three template $\mathrm{T}$ residues, and opposite the two damaged $\mathrm{T}$ residues, $\mathrm{T}$ is incorporated to a lesser extent ( $\approx$ sixfold) than it is opposite the two nondamaged $\mathrm{T}$ residues. Thus, for the incorporation of $\mathrm{T}$, the fidelity opposite the thymine dimer is slightly better than the fidelity opposite the nondamaged templates.

Processivity on Nondamaged and Damaged Templates. Processivity is a measure of the number of deoxynucleotides that a polymerase incorporates before dissociating from the DNA template; thus, it measures the number of deoxynucleotides incorporated per DNA-binding event $(15,19)$. Quantitatively, processivity, $P_{N}$, can be expressed as the probability that following each deoxynucleotide addition $N$, the polymerase will incorporate at least one more deoxynucleotide $N+1$ (15) (see Materials and Methods).

Table 1. Fidelity of Pol $\eta$ on nondamaged and damaged DNA templates

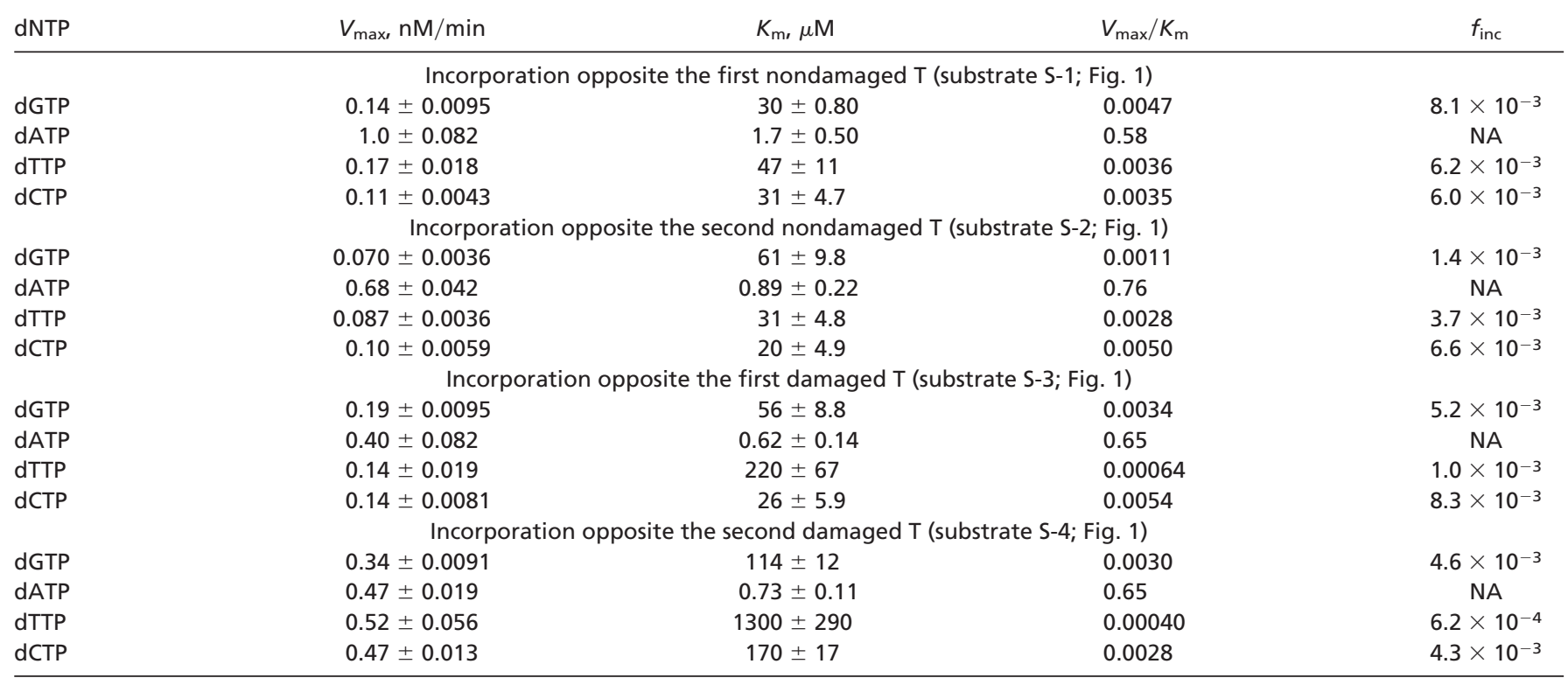

NA, not applicable. 

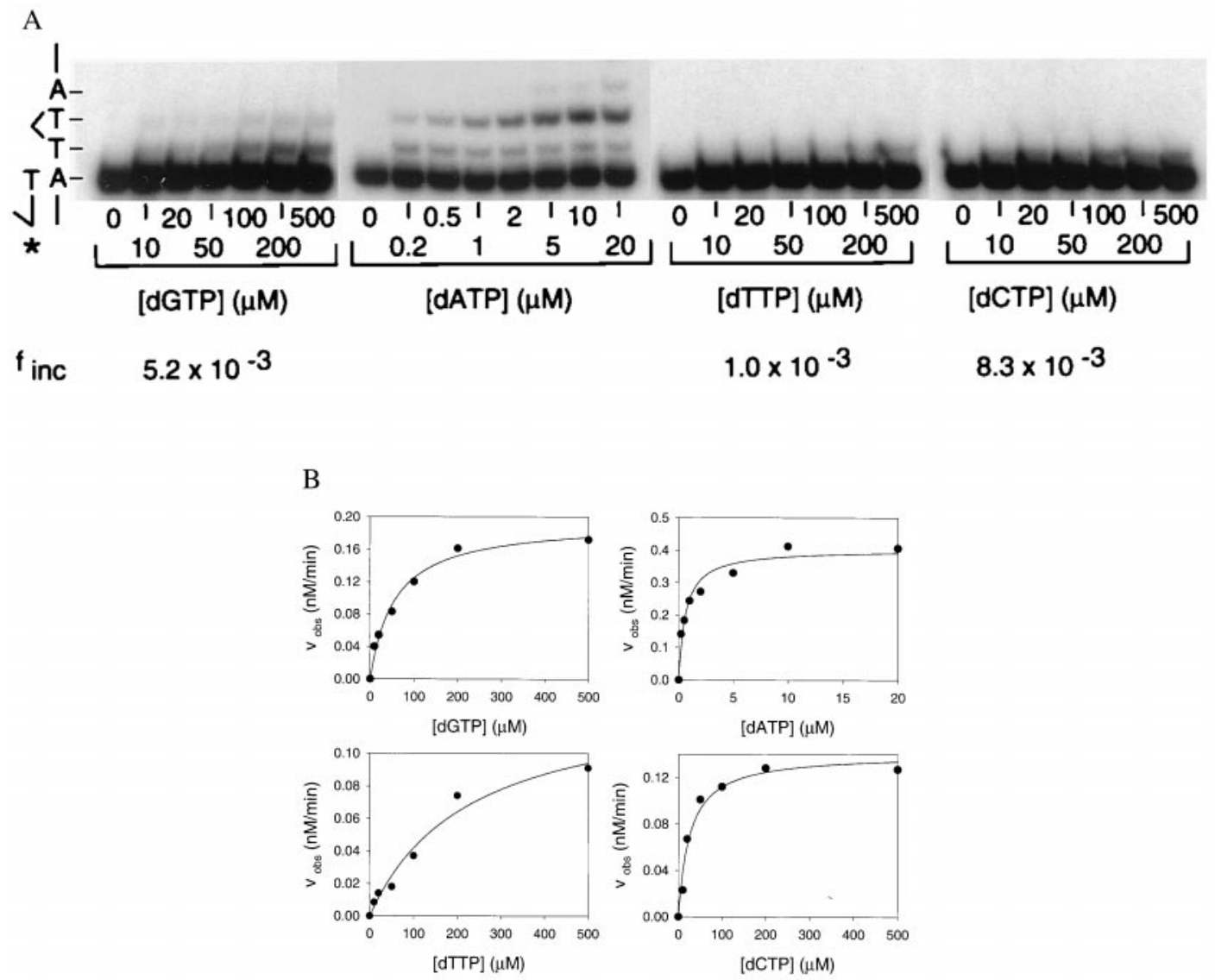

Fig. 3. Fidelity of Pol $\eta$ opposite the first damaged template T of the cis-syn T-T dimer. (A) Deoxynucleotide incorporation across from the first template T of the T-T dimer (substrate S-3; Fig. 1). Pol $\eta(1 \mathrm{nM})$ was incubated for $5 \mathrm{~min}$ at $25^{\circ} \mathrm{C}$ with the primer-template DNA $(10 \mathrm{nM})$ and with increasing concentrations of the incorrect deoxynucleotide (dGTP, dTTP, and dCTP; $0-500 \mu \mathrm{M}$ ) or the correct deoxynucleotide (dATP; $0-20 \mu \mathrm{M}$ ). The reactions were stopped and examined by denaturing PAGE. A portion of the template sequence is shown on the left. The asterisk indicates the ${ }^{32} \mathrm{P}$-labeled $5^{\prime}$ end of the primer. $\widehat{\text { TT, }}$ T-T dimer. (B) Quantitation of the deoxynucleotide incorporation reactions. The observed rate of deoxynucleotide incorporation is plotted as a function of concentration for each of the deoxynucleotides. The data were fit by using Eq. 1, and the $V_{\max }$ and $K_{\mathrm{m}}$ parameters obtained from the fit are listed in Table 1.

The processivity of Pol $\eta$ on both nondamaged (Fig. $5 A$ ) and damaged DNA substrates (Fig. $5 B$ ) was measured by using excess, nonradiolabeled sonicated herring sperm DNA $(1 \mathrm{mg} /$

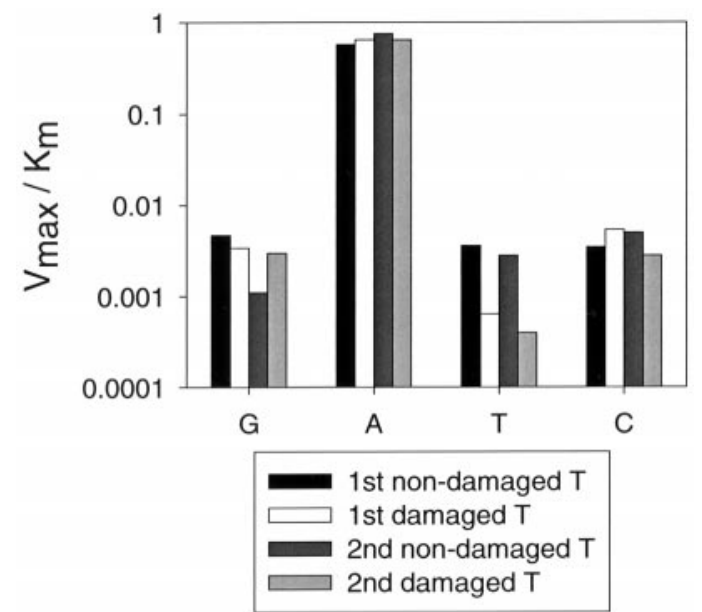

Fig. 4. Comparison of deoxynucleotide incorporation opposite the nondamaged and T-T dimer template residues. The $V_{\max } / K_{m}$ parameters ( $y$ axis) listed in Table 1 are shown for G, A, T, and C incorporation ( $x$ axis) opposite each of the two nondamaged and two damaged template $T$ residues. ml) to trap any Pol $\eta$ molecules dissociating from the DNA template. In lanes 1-4, Pol $\eta$ was preincubated for 15 min with the primer-template DNA substrate before the addition of all four dNTPs (200 $\mu \mathrm{M}$ each), $\mathrm{MgCl}_{2}$, and the DNA trap. In lanes 5-8, Pol $\eta$ was preincubated with the DNA trap and the primer-template DNA substrate before the addition of all four dNTPs and $\mathrm{MgCl}_{2}$. The lack of products in these lanes demonstrates the effectiveness of the sonicated herring sperm DNA as a trap.

For each deoxynucleotide incorporation $N$, we first calculated the percentage of $\mathrm{Pol} \eta$ molecules that incorporated at least $N$ deoxynucleotides as described in Materials and Methods. The percentage of Pol $\eta$ molecules incorporating one deoxynucleotide $(n=1)$ was set at $100 \%$, and for each subsequent addition, the percentage decreased because of the dissociation of the enzyme from the DNA substrate. As shown in Fig. $5 C$, on the nondamaged DNA template, $54 \%$ of the enzyme molecules incorporated at least two deoxynucleotides and 37\% incorporated at least three deoxynucleotides. On the damaged DNA template, $45 \%$ of the enzyme molecules incorporated at least two deoxynucleotides and 31\% incorporated at least three deoxynucleotides.

For each deoxynucleotide incorporation $N$, we next calculated the processivity, $P_{N}$, which is the probability that the polymerase will move ahead after $N$ incorporations to incorporate $N+1$ deoxynucleotides rather than dissociate from the DNA template. To calculate $P_{N}$, we used Eq. 5 (see Materials and Methods). On 

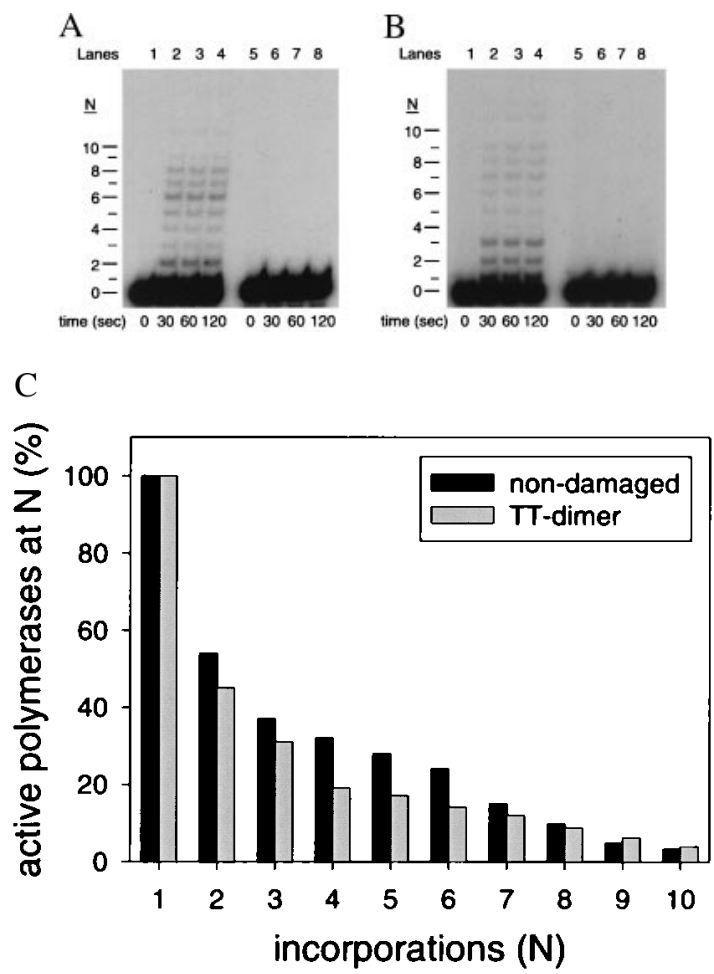

Fig. 5. Processivity of Pol $\eta$ on nondamaged and damaged substrates. $(A)$ Processive DNA synthesis by Pol $\eta$ on an undamaged DNA template (substrate $\mathrm{S}-1$; Fig. 1) resulting from a single binding event. In lanes $1-4$, Pol $\eta(20 \mathrm{nM})$ was preincubated with the undamaged DNA substrate $(10 \mathrm{nM})$ for $15 \mathrm{~min}$ at $25^{\circ} \mathrm{C}$, and reactions were initiated by the addition of all four dNTPs (200 $\mu \mathrm{M}$ each), $\mathrm{MgCl}_{2}(5 \mathrm{mM})$, and the sonicated herring sperm DNA trap $(1 \mathrm{mg} / \mathrm{ml})$. Reactions were stopped after the indicated times, and the samples were examined by denaturing PAGE. The unextended primer $(n=0)$ and the extended primers $(n=1-10)$ are indicated. In lanes $5-8$, Pol $\eta$ was preincubated with the DNA substrate and with the DNA trap, and the reaction was initiated by the addition of dNTPs and $\mathrm{MgCl}_{2}$. (B) Processive DNA synthesis by Pol $\eta$ on the damaged DNA template (substrate S-3; Fig. 1) resulting from a single DNAbinding event. Reactions were performed as described for the undamaged DNA template. (C) Percentage of active Pol $\eta$ molecules at each position along the template. The black bars represent the active polymerases on the nondamaged DNA template and the gray bars represent the active polymerases on the damaged template.

the nondamaged DNA substrate, $P_{N}$ ranged from 0.88 to 0.50 , and the average value was $0.71 \pm 0.13$. On the damaged DNA substrate, the $P_{N}$ ranged from 0.86 to 0.45 , and the average value was $0.73 \pm 0.14$. Additionally, the $P_{N}$ values opposite the first and second nondamaged template T were 0.54 and 0.69 , respectively, whereas the $P_{N}$ values opposite the first and second template T of the dimer were 0.45 and 0.69 , respectively. Thus, the processivity of Pol $\eta$ on the nondamaged and damaged DNA templates is remarkably similar and quite low.

\section{Discussion}

Although Pol $\eta$ bypasses a cis-syn T-T dimer by preferentially incorporating two A residues (5), the accuracy of T-T dimer

1. Sancar, A. (1996) Annu. Rev. Biochem. 65, 43-81.

2. Tang, M., Bruck, I., Eritja, R., Turner, J., Frank, E. G., Woodgate, R., O’Donnell, M. \& Goodman, M. F. (1998) Proc. Natl. Acad. Sci. USA 95, 9755-9760.

3. Reuven, N. B., Tomer, G. \& Livneh, Z. (1998) Mol. Cell 2, 191-199.

4. Nelson, J. R., Lawrence, C. W. \& Hinkle, D. C. (1996) Science 272, 1646-1649

5. Johnson, R. E., Prakash, S. \& Prakash, L. (1999) Science 283, 1001-1004.

6. McDonald, J. P., Levine, A. S. \& Woodgate, R. (1997) Genetics 147, 1557-1568

7. Johnson, R. E., Prakash, S. \& Prakash, L. (1999) J. Biol. Chem. 274, 1597515977. bypass by Pol $\eta$ has remained unclear. Here we show that the error frequency of Pol $\eta$ on both nondamaged- and cis-syn T-T dimer-containing templates is about $10^{-2}$ to $10^{-3}$. Additionally, we show that the processivity of Pol $\eta$ on both nondamaged and damaged templates is quite low, which suggests that Pol $\eta$ would incorporate just a few deoxynucleotides across from the dimer. If, on the average, Pol $\eta$ were to synthesize a patch of four deoxynucleotides for each bypass event, the probability of synthesis without errors in the newly synthesized patch would range from $(0.99)^{4}$ to $(0.999)^{4}$. In that case, the majority of the lesions (96\% or more) will be bypassed by Pol $\eta$ in an error-free manner. Presumably, Pol $\delta$ takes over from Pol $\eta$ once the lesion has been bypassed.

Studies with a single-stranded shuttle vector carrying a sitespecific cis-syn T-T dimer have indicated that replication of such DNA is highly accurate $(\approx 99 \%)$ in $S$. cerevisiae (20). This result suggests that in wild-type yeast cells, DNA polymerase $\zeta$ plays a minor role in the mutagenic replication of such a template, and raises the possibility that a majority of these templates are replicated via the error-free TLS activity of DNA polymerase $\eta$. Inactivation of human Pol $\eta$ in XP variants $(8,9)$ results in UV hypermutability and XP-V cells are impaired in the incorporation of dAMP opposite T-T dimers $(10,11)$. Thus, a deficiency in error-free replicative bypass of cis-syn T-T dimers could be the primary cause of UV hypermutability and of resultant skin cancers in XP-V patients.

Of the eukaryotic DNA polymerases, only Pol $\eta$ is capable of efficiently and correctly bypassing a cis-syn T-T dimer; thus, it is important to understand how Pol $\eta$ accomplishes this. Even though a cis-syn T-T dimer can form correct base pairs with A $(21,22)$, most DNA polymerases stall on encountering this lesion in the template strand. Presumably, this is because most DNA polymerases are highly intolerant of geometric distortions in the DNA caused by the dimer $(23,24)$. The ability of Pol $\eta$ to replicate across from the cis-syn $\mathrm{T}-\mathrm{T}$ dimer may derive from an active site that is more tolerant of DNA distortions, and such a property may enable Pol $\eta$ to use the intrinsic base pairing ability of the dimer. Alternatively, Pol $\eta$ could be an "A rule" polymerase, which inserts A opposite DNA lesions by default (25). However, we consider this unlikely for two reasons. First, as shown here, the fidelity and processivity of deoxynucleotide incorporation opposite nondamaged and damaged DNA templates are very similar. This suggests that Pol $\eta$ incorporates deoxynucleotides opposite nondamaged and damaged templates in a similar manner by using the base pairing ability of both templates. Second, even though Pol $\eta$ does not bypass abasic sites, it predominantly inserts a $G$ residue rather than an $A$ opposite this lesion (unpublished data). Based on these observations, we suggest that Pol $\eta$ has an unusual tolerance for DNA distortions, and this attribute allows Pol $\eta$ to use the base pairing properties of the cis-syn T-T dimer.

We thank Richard Hodge for the T-T dimer. This work was supported by National Institutes of Health Grant GM19261. The construction of the dimer-containing DNA was performed in the Synthetic Organic Chemistry Core Laboratory, which is supported by National Institute of Environmental Health Sciences Center Grant P30-ES06676.

8. Johnson, R. E., Kondratick, C. M., Prakash, S. \& Prakash, L. (1999) Science 285, 263-265.

9. Masutani, C., Kusumoto, R., Yamada, A., Dohmae, N., Yokoi, M., Yuasa, M., Araki, M., Iwai, S., Takio, K. \& Hanaoka, F. (1999) Nature (London) 399, 700-704.

10. Wang, Y.-C., Maher, V. M. \& McCormick, J. J. (1991) Proc. Natl. Acad. Sci. USA 88, 7810-7814.

11. Waters, H. L., Seetharam, S., Seidman, M. M. \& Kraemer, K. H. (1993) J. Invest. Dermatol. 101, 744-748. 
12. Cordeiro-Stone, M., Zaritskaya, L. S., Price, L. K. \& Kaufmann, W. K. (1997) J. Biol. Chem. 272, 13945-13954.

13. Svoboda, D. L., Briley, L. P. \& Vos, J.-M. H. (1998) Cancer Res. 58, 2445-2448.

14. Creighton, S., Bloom, L. B. \& Goodman, M. F. (1995) Methods Enzymol. 262, 232-256.

15. von Hippel, P. H., Fairfield, F. R. \& Dolejsi, M. K. (1994) Ann. N.Y. Acad. Sci. 726, 118-131

16. Echols, H. \& Goodman, M. F. (1991) Annu. Rev. Biochem. 60, 477-511.

17. Goodman, M. F. \& Fygenson, D. K. (1998) Genetics 148, 1475-1482.

18. Fersht, A. (1984) Enzyme Structure and Mechanism (Freeman, New York).
19. Bambara, R. A., Fay, P. J. \& Mallaber, L. M. (1995) Methods Enzymol. 262, 270-280.

20. Gibbs, P. E. M., Kilbey, B. J., Banerjee, S. K. \& Lawrence, C. W. (1993) J. Bacteriol. 175, 2607-2612.

21. Kemmink, J., Boelens, R., Koning, T., van der Marel, G. A., van Boom, J. H. \& Kaptein, R. (1987) Nucleic Acids Res. 15, 4645-4653.

22. Kim, J.-K., Patel, D. \& Choi, B.-S. (1995) Photochem. Photobiol. 62, 44-50.

23. Ciarrocchi, G. \& Pedrini, A. M. (1982) J. Mol. Biol. 155, 177-183.

24. Wang, C.-I. \& Taylor, J.-S. (1991) Proc. Natl. Acad. Sci. USA 88, 9072-9076.

25. Strauss, B. S. (1991) BioEssays 13, 79-84. 